\title{
Correction to: Botulinum Toxin and Pain
}

\author{
Zdravko Lacković
}

\section{Correction to: \\ Chapter "Botulinum Toxin and Pain" in: Z. Lacković, Handbook of Experimental Pharmacology, https://doi.org/10.1007/164_2019_348}

The chapter was inadvertently published without a more specific title according to SEO guidelines. A chapter title needs to be understandable when seen as a standalone item, e.g. on PubMed. The chapter title has now been corrected as 'Botulinum Toxin and Pain'.

The original article was corrected. 